\title{
Atomistic study of segregation and diffusion of yttrium and calcium cations near electrolyte surfaces in solid oxide fuel cells
}

\author{
Yu Sun ${ }^{\mathrm{a}, \mathrm{c}}$, Shotaro Hara ${ }^{\mathrm{b}, \mathrm{c}, *}$ \\ ${ }^{a}$ Institute for Computational Mechanics and Its Applications (NPUiCMA), Northwestern \\ Polytechnical University, Xi'an, Shaanxi, China \\ ${ }^{b}$ Institute of Industrial Science, The University of Tokyo, Komaba 4-6-1, Meguro-ku, \\ Tokyo 153-8505, Japan \\ c JST CREST, Gobancho 7, Chiyoda-ku, Tokyo 102-0076, Japan
}

\begin{abstract}
Segregation behaviors of yttrium (Y) and calcium (Ca) cation dopant species near zirconia (111) surfaces have been investigated utilizing atomistic simulations. The results reveal that surface segregation of both species can be achieved when the density of cation and oxygen vacancies near the surface is relatively high compared to the bulk. Comparing $\mathrm{Y}$ with $\mathrm{Ca}$, the local equilibrium concentration at the surface of $\mathrm{Ca}$ is estimated to be lower than that of Y; however, Ca is kinetically much easier to diffuse from bulk to the surface than Y. The analysis of in-plane cation and oxygen diffusion at Y- or Ca-rich surfaces shows that the cation diffusivity is enhanced with increasing Ca-concentration at the surface, whereas oxygen diffusivity is inhibited. This tendency is more remarkable than that of the Y-rich surface, suggesting that $\mathrm{Ca}$ segregation has a greater negative impact than $\mathrm{Y}$ segregation on
\end{abstract}

\footnotetext{
${ }^{*}$ Corresponding author

Email address: harasho@iis.u-tokyo.ac.jp (Shotaro Hara)

Preprint submitted to Journal of the European Ceramic Society

April 8, 2015
}

(C) 2015. This manuscript version is made available under the Elsevier user license http://www.elsevier.com/open-access/userlicense/1.0/ 
electrolyte performance in solid oxide fuel cells.

Keywords: Solid Oxide Fuel Cells, Segregation, Surface diffusion, Atomistic simulations, Yttria-stabilized zirconia 


\section{Introduction}

Yttria-stabilized zirconia (YSZ) plays an important role as an electrolyte and anode material in energy conversion system such as solid oxide fuel cells (SOFC) due to its high ionic conductivity [1, 2, 3, 4]. It has been

5 recognized that the durability and electrochemical performance of YSZ are strongly related to diffusion properties near YSZ surfaces [5, 6, 17, 8]. For instance, mechanical creep, a typical aging phenomena observed in YSZ [9], is basically driven by the mass transport due to slow cation dynamics under low stress conditions during long-time operation. Among many experimental studies of this complicated phenomenon [10, 11, 12], Laurencin et al. [5] have recently reported that the creep mechanism in Ni-YSZ cermet systems is dominated by cation diffusion at the surface rather than at grain boundaries (GB), particularly when the temperature is close to typical SOFC operating temperature $\left(<1100{ }^{\circ} \mathrm{C}\right)$. Conversely, oxygen diffusion along YSZ surfaces is believed to be a part of critical process directly linked to electrochemical reactions that occur on both the anode and cathode side [13, 14]. Toward designing more efficient fuel cell systems, intensive work using a nano-scale probe has been focused on elucidating oxygen vacancy behavior near the YSZ surface [15].

It is well known that the chemical composition near a YSZ surface differs significantly from that of bulk material, depending on the purity of raw materials or the processing conditions [16, 17, 18, 19]. The difference between bulk and surface composition is primarily produced during the fabrication process in which YSZ experiences high-temperature calcination at approximately $1400{ }^{\circ} \mathrm{C}$ [8]. At this temperature, migration of various types of cation 
defects, such as dopants and impurities (or additives) in the raw materials may be activatied, resulting in surface segregation and change in surface chemical composition. Indeed, according to several experimental studies, after calcination a YSZ surface exhibits considerable enrichment of dopant (Y) and impurities (Ca, Si, Na, etc.), showing the strong depth dependence of the composition profile below the surface [17, 20, 21, 22, 23]. Because the properties of in-plane surface diffusion mentioned above could be strongly affected by impurity levels or the chemical composition at the surface, better understanding of the segregation physics of cation defects in YSZ is essential. However, the resolution ratio limitations and the inability to measure spatial distribution of defects accurately make it difficult to provide detailed insight on cation behavior at a micro-scale.

Atomistic simulations have been widely utilized to clarify the fundamental aspects of segregation and diffusion phenomena associated with oxide systems [24, 25, 26, 27, 28, 29]. With regard to the modeling of segregation processes in YSZ, density functional theory has been applied for accurate measurement of the segregation energy of yttrium near YSZ surfaces or GBs [30, 31]. Lee et al. [32] have successfully predicted yttrium concentrations as a function of the depth from YSZ (100) surface by developing a hybrid Monte Carlo-molecular dynamics algorithm. Besides, the effect of steps existing at the YSZ surface on segregation energetics has been revealed using a reactive force field approach [33, 34]. Yoshiya et al. 35] have examined yttrium segregation energy at various types of YSZ GBs using chemical potential concepts and an empirical potential framework to estimate the local equilibrium con50 centration of yttrium at GBs. Although many numerical studies have been 
conducted, these simulations have relied only on the energetic aspects of the dopant segregation near the surface or GBs. More specifically, in the above studies, energetically stable dopant configurations have been explored based on the exchange algorithm between two cation sites. Although cation diffusion is known to be a thermally activated process via cation vacancy [9, 36], information about cation kinetics under the presence of cation vacancy is strikingly lacking primarily because cation diffusivity is many orders of magnitude lower than that of oxygen. Consequently, accurate tracking of cation hopping within the limited time scale of atomistic simulations becomes chal-

60 lenging [37, 38]. Thus, the underlying mechanisms of cation segregation are not yet fully understood.

The aim of this paper is to provide atomistic insights on the surface segregation of dopant $(\mathrm{Y})$ and impurity $(\mathrm{Ca})$ at the $\mathrm{ZrO}_{2}$ (111) surface, focusing on both energetics and kinetics. We focused on (111) surface since it is the most stable one based on DFT calculations [39. A classical pair-potential, i.e. Buckingham potential coupled with a long-term Coulomb interaction, has been used for all the atomistic simulations. A Ca ion has been selected because $\mathrm{Ca}$ is often employed as a potent dopant to stabilize zirconia, i.e., calcia-stabilized zirconia (CSZ) and is an intrinsic contaminant in bulk YSZ. First, using the same energetic approach as previous work [28, 35], we estimate the segregation energies and the local equilibrium concentrations for $\mathrm{Y}$ and $\mathrm{Ca}$ at the surface. Second, we report the results of nudged elastic band (NEB) analysis toward measuring cation migration barriers near the surface, emphasizing how the presence of both cation and oxygen vacancies surround75 ing the hopping species affects migration barriers. Finally, on the basis of 
our results, we briefly discuss the effect of dopant (or impurity) enrichment on the surface diffusion of the cation and oxygen using standard atomistic techniques, such as kinetic Monte Carlo (KMC) and molecular dynamics (MD).

\section{Method}

\subsection{Computational Model}

The atomistic model is set up as follows. First, a perfect cubic $\mathrm{ZrO}_{2}$ crystal $2.5 \times 2.5 \times 6.8 \mathrm{~nm}$ with $z$-axis as [111] crystal orientation is produced. To simulate $\{111\}$ as the surface, the modeling cell is extended in the $z$ direction by $50 \%$, as shown in Fig. 1. Periodic boundary conditions are imposed on the $x, y$ and $z$ directions. Thus, the distance between neighboring $\{111\}$ surfaces is approximately $3.4 \mathrm{~nm}$.

The interaction between atoms $i$ and $j$ is described by the Buckingham potential coupled with a long-term Coulomb potential, as shown in Eq. (1).

$$
V_{i j}(r)=A \exp \left(-\frac{r_{i j}}{\rho}\right)-\frac{C}{r_{i j}^{6}}+\frac{q_{i} q_{j}}{r_{i j}}
$$

Here, $r_{i j}$ is the distance between atom $i$ and $j . q_{i}$ is the charge of atom $i$. $A, \rho$, and $C$ are empirical parameters that are used for the present work, as shown in Table 1, All the calculations are conducted by in-house code.

By using this YSZ potential, the binding energy for Y with oxygen vacancy as nearest, second nearest and third nearest neighbor are $-0.14,-0.38$ and $-0.19 \mathrm{eV}$, respectively. The position of second nearest neighbor is the most stable one. These results agree with DFT calculation which provided the value of second nearest neighbor as $-0.35 \mathrm{eV}$ [42]. Meanwhile, for the 
(a)

(111) surface
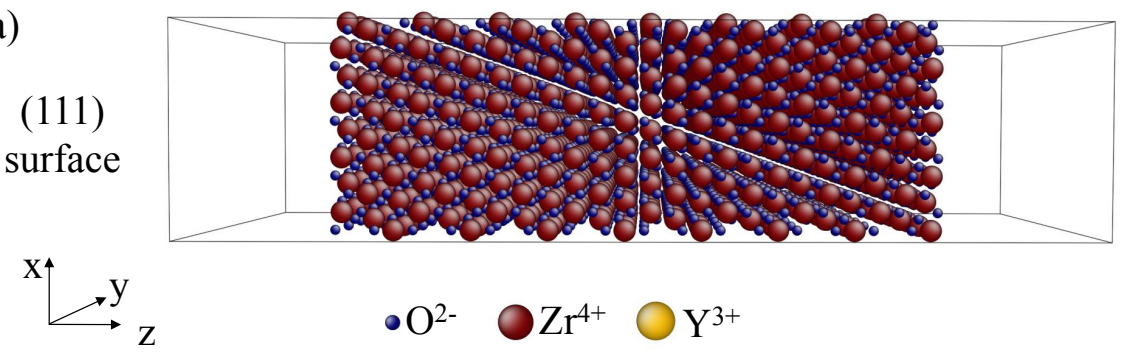

$\cdot \mathrm{O}^{2-} \mathrm{ZZr}^{4+} \mathrm{OY} \mathrm{Y}^{3+}$

(b)

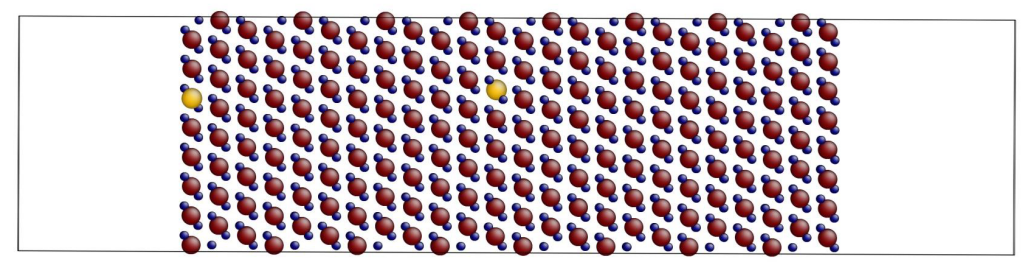

Figure 1: (a) Cubic $\mathrm{ZrO}_{2}$ (111) surface model. (b) Side view of the atomistic configuration consisting of one $\mathrm{Y}_{\mathrm{Zr}}^{\prime}$ at the first layer, one $\mathrm{Y}_{\mathrm{Zr}}^{\prime}$ and $\mathrm{V}_{\mathrm{O}}^{\bullet \bullet}$ at the bulk layer. $\mathrm{Zr}^{4+}, \mathrm{Y}^{3+}$, and $\mathrm{O}^{2-}$ ions are shown as red, yellow, and blue, respectively.

case of oxygen vacancy and $\mathrm{Ca}$, three values are $-0.67,-0.72$ and $-0.36 \mathrm{eV}$ by the present $\mathrm{Ca}-\mathrm{O}$ potential. Such results are in accordance with the previous study on defect structure of calcia-stabilized zirconia which declared second nearest neighbor as the most stable one as well $(-0.68 \mathrm{eV})$ [43]. Hence, it is deemed that the potentials for both $\mathrm{Y}$ and $\mathrm{Ca}$ are available here.

Besides, large model with size of twice the vacuum gap and lateral dimension has been used to calculate the segregation energy for defect complexes at surface layer. The results of this large model are respectively $-0.78,-1.94$ and $-2.03 \mathrm{eV}$ for $\mathrm{Y}, \mathrm{Ca}$ and cation vacancy, which are similar with the values of our original model. Thus, size effect would be minor and will not cause any computational inaccuracies. 
Table 1: Buckingham potential parameters employed in the present calculations [40, 41].

\begin{tabular}{llll}
\hline Interaction & $\mathrm{A}[\mathrm{eV}]$ & $\rho[\AA]$ & $C\left[\mathrm{eV} \AA^{6}\right]$ \\
\hline $\mathrm{Y}^{3+}-\mathrm{O}^{2-}$ & 1325.6 & 0.3461 & 0.0 \\
$\mathrm{Ca}^{2+}-\mathrm{O}^{2-}$ & 784.38 & 0.36356 & 0.0 \\
$\mathrm{Zr}^{4+}-\mathrm{O}^{2-}$ & 1024.6 & 0.376 & 0.0 \\
$\mathrm{O}^{2-}-\mathrm{O}^{2-}$ & 22764.0 & 0.149 & 27.89 \\
\hline
\end{tabular}

\subsection{Segregation energy of cation defect}

To investigate the surface segregation behavior of cation defects, stable atomic configurations containing the defects located layer by layer from the surface to the bulk region are computed by conjugate gradient relaxation. Three types of cation defects ( $\mathrm{Y}^{3+}$ dopant, $\mathrm{Ca}^{2+}$ impurity, and $\mathrm{Zr}^{4+}$ vacancy) are considered in this work (Table 2).

Table 2: Lists of cation defect types considered in this study. Each defect is represented by Kröger-Vink notation.

\begin{tabular}{ccc}
\hline & \multicolumn{2}{c}{ Type of defect } \\
Cation defect & isolated & complexes \\
\hline $\mathrm{Y}^{3+}$ dopant & $\mathrm{Y}_{\mathrm{Zr}}^{\prime}$ & $\left(2 \mathrm{Y}_{\mathrm{Zr}}^{\prime}, \mathrm{V}_{\mathrm{O}}^{\bullet \bullet}\right)^{\times}$ \\
$\mathrm{Ca}^{2+}$ impurity & $\mathrm{Ca}_{\mathrm{Zr}}^{\prime \prime}$ & $\left(\mathrm{Ca}_{\mathrm{Zr}}^{\prime \prime}, \mathrm{V}_{\mathrm{O}}^{\bullet \bullet}\right)^{\times}$ \\
$\mathrm{Zr}^{4+}$ vacancy & $\mathrm{V}_{\mathrm{Zr}}^{4 \prime}$ & $\left(\mathrm{V}_{\mathrm{Zr}}^{4 \prime}, 2 \mathrm{~V}_{\mathrm{O}}^{\bullet \bullet}\right)^{\times}$ \\
\hline
\end{tabular}

For a 3-valence cation dopant such as $\mathrm{Y}^{3+}$, one more ion substitute $\mathrm{Zr}^{4+}$ at arbitrary positions in the system maintain the charge neutrality by removing the corresponding number of oxygen ions. Using Kröger-Vink notation, two 
types of point defects, i.e., $\mathrm{Y}_{\mathrm{Zr}}^{\prime}$ as the $\mathrm{Y}^{3+}$ cation substituting $\mathrm{Zr}^{4+}$ and $\mathrm{V}_{\mathrm{O}}^{\bullet \bullet}$ as the oxygen vacancies, have been introduced into the system.

$$
\mathrm{Y}_{2} \mathrm{O}_{3} \rightarrow 2 \mathrm{Y}_{\mathrm{Zr}}^{\prime}+\mathrm{V}_{\mathrm{O}}^{\bullet \bullet}+3 \mathrm{O}_{\mathrm{O}}^{\times}
$$

To discuss the effect of impurity species, a $\mathrm{Ca}^{2+}$ cation is considered by replacing one $\mathrm{Zr}^{4+}$ and removing one oxygen ion, as follows:

$$
\mathrm{CaO} \rightarrow \mathrm{Ca}_{\mathrm{Zr}}^{\prime \prime}+\mathrm{V}_{\mathrm{O}}^{\bullet \bullet}+\mathrm{O}_{\mathrm{O}}^{\times}
$$

Because the movement of dopant or impurity is accompanied by site exchange with cation vacancy, the segregation of cation vacancy is also taken into account by removing $\mathrm{Zr}^{4+}$, denoted as $\mathrm{V}_{\mathrm{Zr}}^{4 \prime}$ as:

$$
\mathrm{ZrO}_{2} \rightarrow \mathrm{V}_{\mathrm{Zr}}^{4 \prime}+2 \mathrm{~V}_{\mathrm{O}}^{\bullet \bullet}+2 \mathrm{O}_{\mathrm{O}}^{\times}
$$

For each cation defect, several types of defect complexes are possible, depending on the positions of the oxygen vacancies. In this work, the isolated cation defect and the charge-neutralized defect complexes (Table 2) are examined.

The segregation energy $E_{i, \text { seg }}$ of a cation defect at the $i$ th layer from the surface is defined as Eq. (5)

$$
E_{i, \mathrm{seg}}=E_{i, \mathrm{surf}}-E_{\mathrm{bulk}}
$$

where $E_{i, \text { surf }}$ is the relaxed energy of the configurations containing a cation defect at the $i$ th layer from surface, and $E_{\text {bulk }}$ is the energy of configuration with the corresponding defect at bulk (sufficiently far from the surface) [35]. For the case of defect complexes, the oxygen vacancies are set at the nearest 
or second-nearest neighbor of the cation defect. Then, by performing energy minimization for all possible positions of oxygen vacancies, the energy of the most stable configuration is applied as $E_{i, \text { surf }}$ Fig. 1(b) shows a typical side view of the atomistic configuration to compute $E_{1 \text {,surf }}$ of $\mathrm{Y}_{\mathrm{Zr}}^{\prime}$, in which one $\mathrm{Y}_{\mathrm{Zr}}^{\prime}$ is placed at the first layer of the $\{111\}$ surface while the remaining $\mathrm{Y}_{\mathrm{Zr}}^{\prime}$ and $\mathrm{V}_{\mathrm{O}}^{\bullet \bullet}$ are positioned at the bulk.

\subsection{Cation defect migration energy}

The activation energy barriers of cation hopping for $\mathrm{Y}_{\mathrm{Zr}}^{\prime}, \mathrm{Ca}_{\mathrm{Zr}}^{\prime \prime}$, and $\mathrm{Zr}^{\times}$ are obtained with the aid of reaction pathway analysis. This analysis is performed using an NEB method [44], which we have previously applied to the barrier measurement of defect nucleation in various solid systems [45, 46. The input to the NEB method is an initial estimation of the energy pathway composed of a string of 13 images. The initial image corresponds to the energy-minimized structure in which the cation and cation vacancy are introduced at the site of the $i$ th layer and its nearest neighbor site at the $j$ th layer, respectively. The final image is the relaxed structure after changing the positions of the corresponding cation and cation vacancy. The intermediate images are provided by connecting the two endpoints by linear interpolation. The convergence is determined when the potential force on each replica vertical to the path becomes less than $1.0 \times 10^{-5} \mathrm{eV} / \AA$ [45, 46]. The activation energies $E_{i \rightarrow j}$ for cation hopping from the $i$ th layer to the $j$ th layer have been computed for the top six layers denoted as $i(=1 \ldots 6)$ with three different directions denoted as $j=i-1, i$, and $i+1$ (two directions when $i=1)$.

${ }_{145}$ Similar to the segregation energy analysis, to investigate the effect of 
oxygen vacancies on cation migration, the barriers are estimated under different local environments of oxygen vacancies $\mathrm{V}_{\mathrm{O}}^{\bullet \bullet}$ around the activated cation $\left(\mathrm{Y}_{\mathrm{Zr}}^{\prime}, \mathrm{Ca}_{\mathrm{Zr}}^{\prime \prime}\right.$, and $\left.\mathrm{Zr}^{\times}\right)$. In this study, two systems, which we refer to as the defect-isolated and defect-complexes systems, are considered. In the defectIn the defect-complexes system, the cation is activated under more complicated conditions. The charge-neutralized defects are combined such as $\left(2 \mathrm{Y}_{\mathrm{Zr}}^{\prime}, \mathrm{V}_{\mathrm{O}}^{\bullet \bullet}\right)^{\times}\left(\mathrm{V}_{\mathrm{Zr}}^{4 \prime}, 2 \mathrm{~V}_{\mathrm{O}}^{\bullet \bullet}\right)^{\times},\left(\mathrm{Ca}_{\mathrm{Zr}}^{\prime \prime}, \mathrm{V}_{\mathrm{O}}^{\bullet \bullet}\right)^{\times}\left(\mathrm{V}_{\mathrm{Zr}}^{4 \prime}, 2 \mathrm{~V}_{\mathrm{O}}^{\bullet \bullet}\right)^{\times}$, and $\mathrm{Zr}^{\times}\left(\mathrm{V}_{\mathrm{Zr}}^{4 \prime}, 2 \mathrm{~V}_{\mathrm{O}}^{\bullet \bullet}\right)^{\times}$. In the analysis of defect-complexes system, five samples are prepared, in which each has the randomly chosen $\mathrm{V}_{\mathrm{O}}^{\bullet}$ positions. Since the calculations for all the cases are computationally difficult, the mean values and standard deviation of $E_{i \rightarrow j}$ for five samples are estimated.

\section{Results and discussion}

\subsection{Segregation Energy}

Fig. 2 displays the energy of a cation defect at the surface relative to that in the bulk as a function of layer number from the surface. From Fig. 2(a) and (b), it is evident that the segregation energy values for the isolated $\mathrm{Y}_{\mathrm{Zr}}^{\prime}$ and $\mathrm{Ca}_{\mathrm{Zr}}^{\prime \prime}$ are positive from the second layer to the bulk and that the maximum occurs at the second layer. This indicates energy-instability when an isolated defect is positioned away from the surface, which could be attributed to the reduction of binding energy involving $\mathrm{Y}_{\mathrm{Zr}}^{\prime}-\mathrm{V}_{\mathrm{O}}^{\bullet \bullet}$ and $\mathrm{Ca}_{\mathrm{Zr}}^{\prime \prime}-\mathrm{V}_{\mathrm{O}}^{\bullet \bullet}$ by setting $\mathrm{V}_{\mathrm{O}}^{\bullet \bullet}$ far from $\mathrm{Y}_{\mathrm{Zr}}^{\prime}$ or $\mathrm{Ca}_{\mathrm{Zr}}^{\prime \prime}$. Moreover, since the effective charges of $\mathrm{Y}_{\mathrm{Zr}}^{\prime}$ are one more than that of $\mathrm{Ca}_{\mathrm{Zr}}^{\prime \prime}$, the interaction of $\mathrm{Ca}_{\mathrm{Zr}}^{\prime \prime}-\mathrm{V}_{\mathrm{O}}^{\bullet \bullet}$ is greater, leading to the higher positive value of $\mathrm{Ca}_{\mathrm{Zr}}^{\prime \prime}$. Note that values for both $\mathrm{Y}_{\mathrm{Zr}}^{\prime}(-0.08 \mathrm{eV})$ and 
170 reductions could be attributed to the release of strain energy at the surface. Strain energy is accumulated in the bulk because the atomic radii of $\mathrm{Y}^{3+}$ $(1.019 \AA)$ and $\mathrm{Ca}^{2+}(1.120 \AA)$ are larger than that of the host cation $\mathrm{Zr}^{4+}$ $(0.840 \AA)$. Indeed, the energy reduction of $\mathrm{Ca}_{\mathrm{Zr}}^{\prime \prime}$ is larger than that of $\mathrm{Y}_{\mathrm{Zr}}^{\prime}$, 175 which is consistent with the fact that the atomic radius of $\mathrm{Ca}^{2+}$ is larger than that of $\mathrm{Y}^{3+}$.

Segregation energy is obviously different for co-segregation with oxygen vacancies. The segregation energy values for $\left(2 \mathrm{Y}_{\mathrm{Zr}}^{\prime}, \mathrm{V}_{\mathrm{O}}^{\bullet \bullet}\right)^{\times}$and $\left(\mathrm{Ca}_{\mathrm{Zr}}^{\prime \prime}, \mathrm{V}_{\mathrm{O}}^{\bullet \bullet}\right)^{\times}$ become approximately zero from the fifth layer to the bulk. From the fourth 180 layer to the surface, the values are negative with larger absolute values approaching the surface. The maximum occurs at the first layer $\left(\left(2 \mathrm{Y}_{\mathrm{Zr}}^{\prime}, \mathrm{V}_{\mathrm{O}}^{\bullet \bullet}\right)^{\times}\right.$ $\left.=-0.77 \mathrm{eV},\left(\mathrm{Ca}_{\mathrm{Zr}}^{\prime \prime}, \mathrm{V}_{\mathrm{O}}^{\bullet \bullet}\right)^{\times}=-1.98 \mathrm{eV}\right)$. In the defect complexes case, the effect of binding energy becomes weaker because the oxygen vacancy is accompanied by a cation. The strain relaxation induced by vacancy and cation co-segregation is a significant component of segregation energy and leads to the negative values in the first to the fourth layers. Therefore, it can be concluded that higher concentration of oxygen vacancies at the surface than at the bulk is associated with the enrichment of both Y and Ca at the surface. These results are similar to the tendency for GB segregation for Y reported by Yoshiya et al. [35].

Comparison with the results of defect-isolated and defect-complexes structures shows that the values of segregation energy are significantly influenced by electrostatic interaction of oxygen vacancy. Hence, to clarify the effect of long-range electrostatic interaction, analysis on segregation energy has been 

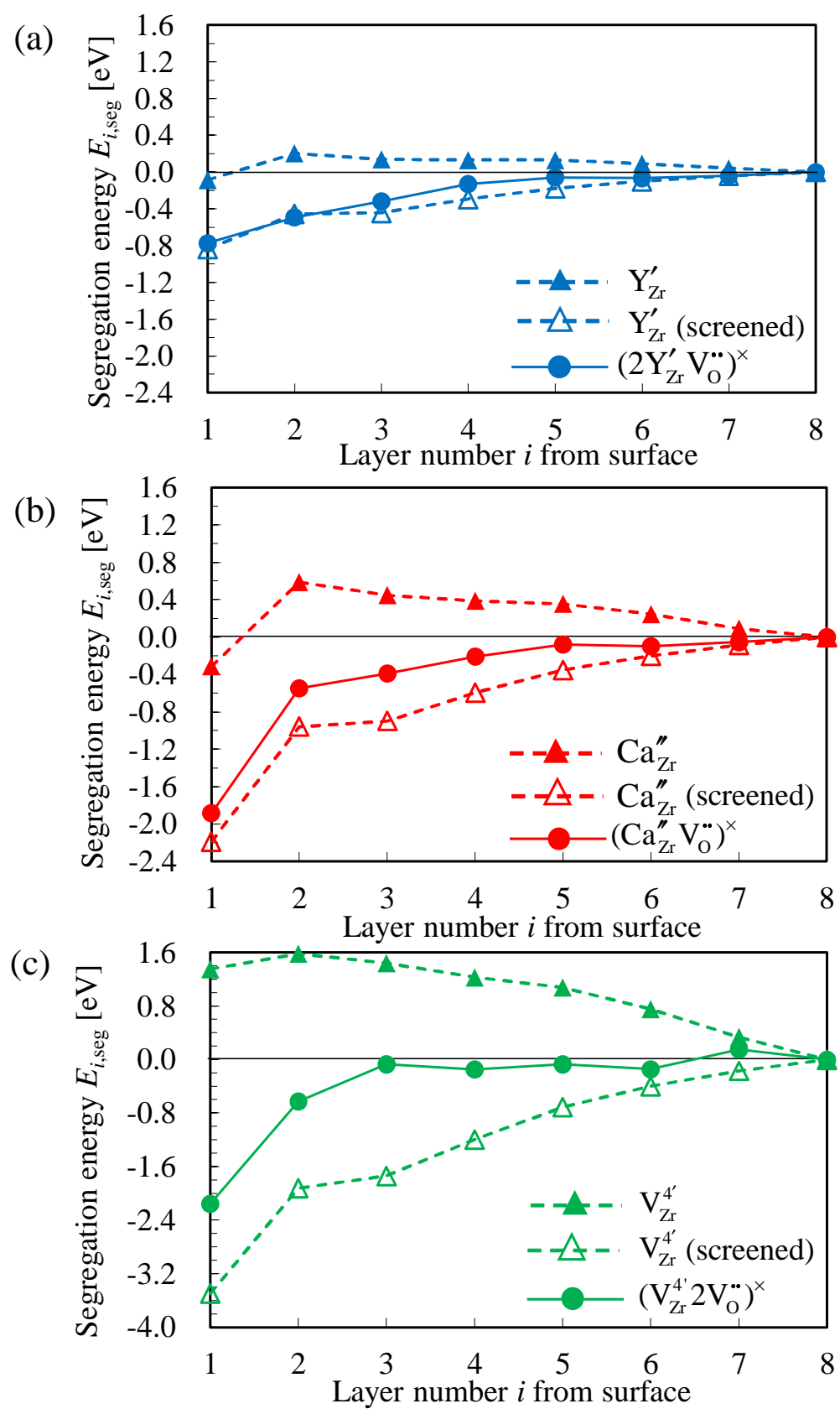

Figure 2: Segregation energy for cases in Table 2 and the situations for defect-isolated with electrostatic energy screened.

$$
\text { (a) } \begin{aligned}
\mathrm{Y}_{\mathrm{Zr}}^{\prime} \text { and }\left(2 \mathrm{Y}_{\mathrm{Zr}}^{\prime}, \mathrm{V}_{\mathrm{O}}^{\bullet \bullet}\right)^{\times} \text {. } & \text { (b) } \mathrm{C}_{1}^{\prime \prime} \mathrm{l}_{\mathrm{r}}^{\prime \prime} \text { and }\left(\mathrm{Ca}_{\mathrm{Zr}}^{\prime \prime}, \mathrm{V}_{\mathrm{O}}^{\bullet \bullet}\right)^{\times} \text {. (c) } \mathrm{V}_{\mathrm{Zr}}^{4 \prime} \text { and } \\
& \left(\mathrm{V}_{\mathrm{Zr}}^{4 \prime}, 2 \mathrm{~V}_{\mathrm{O}}^{\bullet \bullet}\right)^{\times}
\end{aligned}
$$


195 As Fig. 2, for the cases of defect-isolated structures, the segregation energy turns to be negative when electrostatic energy is screened. Therefore, it is clear that the long-range electrostatic interaction between $\mathrm{V}_{\mathrm{O}}^{\bullet \bullet}$ and dopant is the dominant factor of the positive segregation energy.

200 In addition, we calculated the segregation energy of $\mathrm{V}_{\mathrm{Zr}}^{4 \prime}$ accompanied by $\mathrm{V}_{\mathrm{O}}^{\bullet \bullet}$ and far from $\mathrm{V}_{\mathrm{O}}^{\bullet \bullet}$. The results (Fig. 2(c)) show that the segregation of cation vacancy $\mathrm{V}_{\mathrm{Zr}}^{4 \prime}$ is also enhanced by accompanying oxygen vacancies $\mathrm{V}_{\mathrm{O}}^{\bullet \bullet}$. Compared with the results for $\left(2 \mathrm{Y}_{\mathrm{Zr}}^{\prime}, \mathrm{V}_{\mathrm{O}}^{\bullet \bullet}\right)^{\times}$and $\left(\mathrm{Ca}_{\mathrm{Zr}}^{\prime \prime}, \mathrm{V}_{\mathrm{O}}^{\bullet \bullet}\right)^{\times}$, the energy gain of $\left(\mathrm{V}_{\mathrm{Zr}}^{4 \prime}, 2 \mathrm{~V}_{\mathrm{O}}^{\bullet \bullet}\right)^{\times}$at the first layer $(-2.16 \mathrm{eV})$ is approximately the same 205

as $\left(\mathrm{Ca}_{\mathrm{Zr}}^{\prime \prime}, \mathrm{V}_{\mathrm{O}}^{\bullet \bullet}\right)^{\times}$but much larger than that of $\left(2 \mathrm{Y}_{\mathrm{Zr}}^{\prime}, \mathrm{V}_{\mathrm{O}}^{\bullet \bullet}\right)^{\times}$. Here, it is noted that the strong segregation tendency of cation vacancy, which has not been reported in previous theoretical works, is in good agreement with recent experimental findings using X-ray diffraction, i.e., the topmost YSZ (111) surface exhibits a high density of both cation and oxygen vacancies [22].

Our calculations imply that both $\mathrm{Y}$ and $\mathrm{Ca}$ are likely to remain at $\mathrm{ZrO}_{2}(111)$ surface. These results are supported by previous qualitative experiments [20, 22, 33]. However, the analysis here is focused on the diluteconcentration case of defects without considering defects interaction. In the next subsection, defect interaction is considered and segregation concentra215

\subsection{Equilibrium Segregation Concentrations}

Based on the framework previously reported by Yoshiya et al., the local equilibrium concentrations of a dopant at the surface $\left(C_{\mathrm{s}}^{\text {eq }}\right)$ have been considered as well as the interactions between defects [35, 48]. As local con- 

that of bulk.

$$
\mu_{\mathrm{s}}\left(C_{\mathrm{s}}^{\mathrm{eq}}\right)=\mu_{\mathrm{b}}\left(C_{\mathrm{b}}\right)
$$

Here, $\mu_{\mathrm{s}}\left(C_{\mathrm{s}}\right)$ or $\mu_{\mathrm{b}}\left(C_{\mathrm{b}}\right)$ under $0 \mathrm{~K}$ conditions can be defined as

$$
\mu(n)=\mathrm{d} E_{\text {total }}(n) / \mathrm{d} n
$$

where $n$ is the number of dopant cations at the surface (or bulk) and is simply related to $C=n / n_{\text {tot }}$ using the total number of cations $n_{\text {tot }}$ at the surface (or bulk), $E_{\text {total }}(n)$ is the whole potential energy of the relaxed configuration containing $n$ dopant cations at the surface (or bulk). Numerically, Eq. (7) can be approximated as

$$
\mu(n)=\left[E_{\text {total }}(n+\delta)-E_{\text {total }}(n-\delta)\right] / 2 \delta
$$

where $\delta$ is the increment of the dopant added to the system.

In this study, the insertion of defect complexes $\left(2 \mathrm{Y}_{\mathrm{Zr}}^{\prime}, \mathrm{V}_{\mathrm{O}}^{\bullet \bullet}\right)^{\times}$or $\left(\mathrm{Ca}_{\mathrm{Zr}}^{\prime \prime}, \mathrm{V}_{\mathrm{O}}^{\bullet \bullet}\right)^{\times}$ are considered and $\delta=4$ is used. For the computation of $\mu_{\mathrm{s}}(n), n / 2$ number 235 of $\left(2 \mathrm{Y}_{\mathrm{Zr}}^{\prime}, \mathrm{V}_{\mathrm{O}}^{\bullet \bullet}\right)^{\times}$or $n$ number of $\left(\mathrm{Ca}_{\mathrm{Zr}}^{\prime \prime}, \mathrm{V}_{\mathrm{O}}^{\bullet \bullet}\right)^{\times}$are introduced into the surface model. The dopants are randomly exchanged with $\mathrm{Zr}$ at the outermost layer, and the oxygen vacancies associated with each dopants are also randomly set 
at the first or second nearest positions of the dopants. Using a similar procedure, computation of $\mu_{\mathrm{b}}(n)$ is also performed for a bulk $\mathrm{ZrO}_{2}$ model $(2.5$ $\times 2.5 \times 6.8 \mathrm{~nm})$ containing the corresponding number of defect complexes. To reduce the statistical error [48], the relaxed energy of $E_{\text {total }}(n)$ has been estimated by averaging over 100 samples with different positions of defect complexes of $\left(2 \mathrm{Y}_{\mathrm{Zr}}^{\prime}, \mathrm{V}_{\mathrm{O}}^{\bullet \bullet}\right)^{\times}$or $\left(\mathrm{Ca}_{\mathrm{Zr}}^{\prime \prime}, \mathrm{V}_{\mathrm{O}}^{\boldsymbol{\bullet}}\right)^{\times}$, for the surface and bulk models, respectively.

245 The results are shown in Fig. 3. As shown in Fig. 3(a), the chemical potential of Y at bulk is initially determined to be $\mu_{\mathrm{b}}\left(C_{\mathrm{b}}\right)=40.48 \mathrm{eV}$ when $C_{\mathrm{b}}=18.2$ atom\%, which corresponds to the most common $10 \mathrm{~mol} \%$ YSZ system $(10 \mathrm{YSZ}, \mathrm{Y} / \mathrm{Zr}=0.22)$. The results also show that the chemical potential at surface $\mu_{\mathrm{s}}$ increases almost linearly as the dopant concentration $C_{\mathrm{s}}$ increases. These results show that local equilibrium conditions $\mu_{\mathrm{s}}\left(C_{\mathrm{s}}^{\mathrm{eq}}\right)=\mu_{\mathrm{b}}\left(C_{\mathrm{b}}\right)$ are achieved when the dopant concentrations at the outermost layer reaches $C_{\mathrm{s}}^{\mathrm{eq}}=46$ atom\% (29.9 mol\% YSZ, Y/Zr=0.85), which gives an enrichment factor $\alpha=3.86$. The obtained concentration is approximately twice as high as that estimated for $\mathrm{Y}$ segregation at $\mathrm{ZrO}_{2}$ GBs using the same approach ( $\sim 25$ atom\%) [35, indicating that dopant segregation at (111) surface is more pronounced than at GBs. Furthermore, according to recent experimental observations of a YSZ (111) surface using high-resolution X-ray photoemission spectroscopy [33], the outermost surface has approximately 45 atom\% Y enrichment, which is in good agreement with our estimation and strongly supports the validity of our calculations.

As shown in Fig. 3(b), the behavior of chemical potentials at the surface of $\mathrm{Ca}$ is similar to that of Y. For comparison, assuming $C_{\mathrm{b}}=10.0$ atom\% (10 

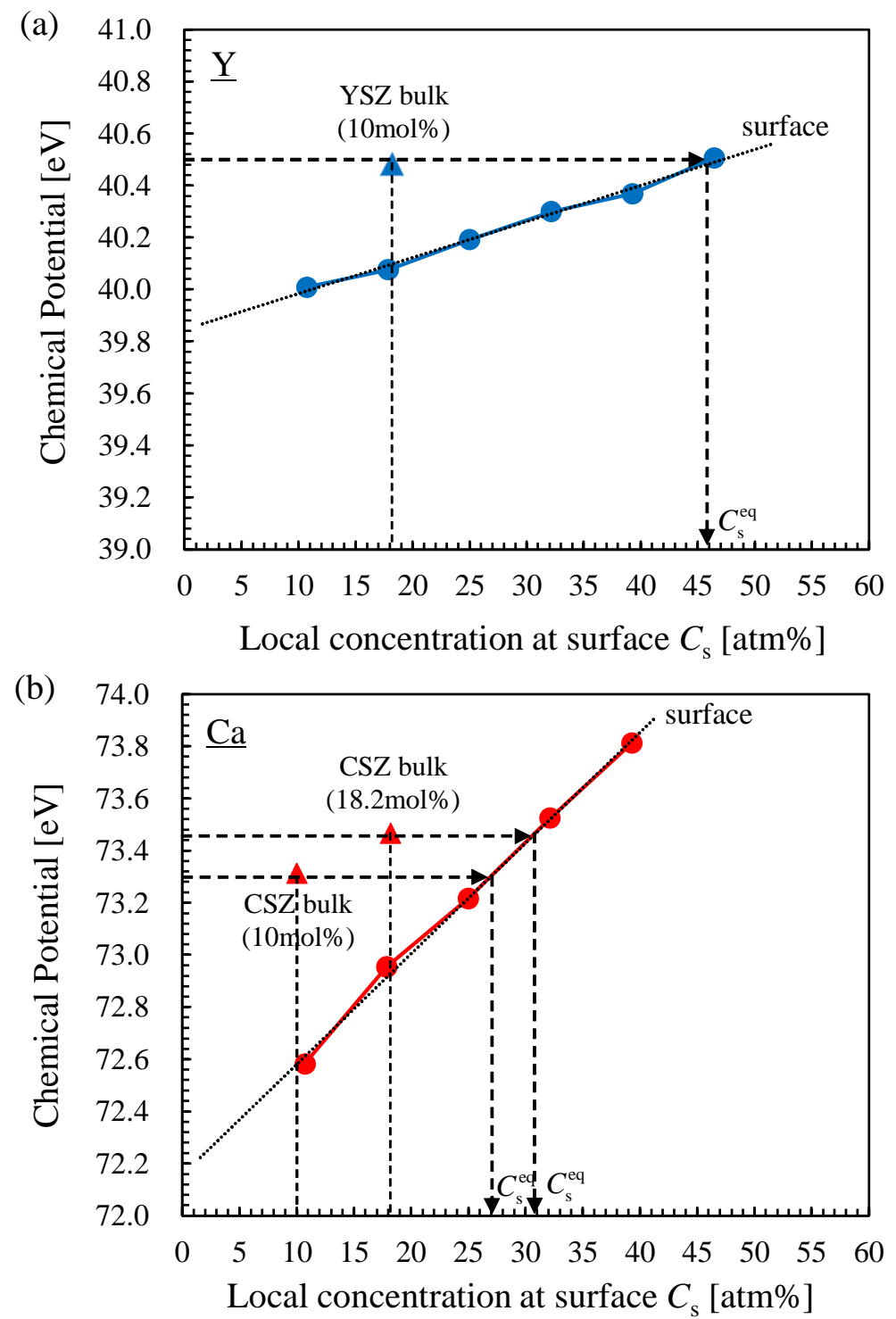

Figure 3: Chemical potentials as a function of local dopant concentration at the outermost layer for (a) Y and (b) Ca. For comparison, the bulk values for both cations are also shown. 
mol\% CSZ, $\mathrm{Ca} / \mathrm{Zr}=0.11$ ), which has an identical molar fraction to 10YSZ, the local equilibrium concentration at the outermost layer for $\mathrm{Ca}$ is estimated to be approximately $C_{\mathrm{s}}^{\mathrm{eq}}=27 \mathrm{~atm} \%(\mathrm{Ca} / \mathrm{Zr}=0.37, \alpha=3.36)$. In addition, if we consider the bulk of $C_{\mathrm{b}}=18.2$ atom\% $(18.2 \mathrm{~mol} \% \mathrm{CSZ}, \mathrm{Ca} / \mathrm{Zr}=0.22)$, which has the same atom fraction as $10 \mathrm{YSZ}, C_{\mathrm{s}}^{\mathrm{eq}}=31 \mathrm{~atm} \%(\mathrm{Ca} / \mathrm{Zr}=0.45$, $\alpha=2.05)$ is obtained. Thus, we find that, for both typical cases, the local equilibrium concentration at the outermost layer $C_{\mathrm{s}}^{\mathrm{eq}}$ and the enrichment factor $\alpha$ for Ca are smaller than those of $\mathrm{Y}$.

It should be noted that the surface segregation at the outermost layer of $\left(\mathrm{Ca}_{\mathrm{Zr}}^{\prime \prime}, \mathrm{V}_{\mathrm{O}}^{\bullet \bullet}\right)^{\times}$in a dilute-concentration system is remarkably stable compared to $\left(2 \mathrm{Y}_{\mathrm{Zr}}^{\prime}, \mathrm{V}_{\mathrm{O}}^{\bullet \bullet}\right)^{\times}$, as shown in Fig. 2, Fig. 3(a) and (b) also illustrate that the difference in chemical potential energy between the surface and bulk $(\Delta \mu=$ $\left.\mu_{\mathrm{s}}-\mu_{\mathrm{b}}\right)$ for $\mathrm{Ca}$, which represents a driving force of segregation, is larger than that of $\mathrm{Y}$ at a lower concentration of approximately 10 atom\%. However, the gradient of chemical potential with respect to the surface concentration $\left(\partial \mu_{\mathrm{s}} / \partial C_{\mathrm{s}}\right)$ for $\mathrm{Ca}$ is steeper than that of $\mathrm{Y}$ by a factor of approximately three, which results in the quick reduction of driving force $\Delta \mu$ with increasing $C_{\mathrm{s}}$ and finally satisfies $\Delta \mu=0$ condition at lower concentrations than Y. This gradient difference could be attributed to the following factor. The number of oxygen vacancies accommodated at the Ca-segregated surface is two times as large as that at the $\mathrm{Y}$-segregated surface when the number of $\mathrm{Ca}_{\mathrm{Zr}}^{\prime \prime}$ and $\mathrm{Y}_{\mathrm{Zr}}^{\prime}$ is identical. The higher oxygen vacancy density will naturally lead to higher defect-defect interactions. The gradient difference could also be attributed to the ionic size mismatch between these cations and the host cation. The larger radius of $\mathrm{Ca}_{\mathrm{Zr}}^{\prime \prime}$ than $\mathrm{Y}_{\mathrm{Zr}}^{\prime}$ may make it relatively easier for high strain energy to 
accumulate near the surface as defect defect concentration increases, which contributes to the suppression of dopant accumulation.

The current analysis clearly demonstrates that consideration of defectdefect interactions is essential for understanding surface segregation energetics. Although we assumed that surface enrichment was limited to the outermost layer, it has been reported that Y enrichment involves the second layer or even inner layers, thus reducing Y concentrations. Further analysis of the chemical potential associated inner layers could provide a more quantitative connection between experimental observations and theoretical investigations.

\subsection{Migration Barrier Analysis}

Migration energy results for $\mathrm{Y}_{\mathrm{Zr}}^{\prime}, \mathrm{Ca}_{\mathrm{Zr}}^{\prime \prime}$ and $\mathrm{Zr}^{\times}$between the $i$ and $j$ th layers from the surface in defect-isolated systems are listed in Tables 3 - 5 , respectively. The migration energy in defect-complexes systems is summarized in Tables $6-8$.

To investigate the boundary layer between the surface and bulk where the change of kinetic behavior is observable, we calculate the averaged values of $305 \quad E_{i \rightarrow i+1}, E_{i \rightarrow i}$ and $E_{i \rightarrow i-1}$, as follows.

$$
E_{i, \text { ave }}=\frac{E_{i \rightarrow i+1}+E_{i \rightarrow i}+E_{i \rightarrow i-1}}{3}
$$

In Fig. 4, we provide the corresponding data for $E_{i \text {,ave }}$ as a function of the layer number from the surface for both defect-isolated and defectcomplexes systems. Fig. 4(a) shows that the average energy barriers remain almost constant from the third layer to the bulk $\left(\mathrm{Zr}^{\times}(\sim 4.8 \mathrm{eV})>\mathrm{Y}_{\mathrm{Zr}}^{\prime}(\sim 4.3\right.$ 
Table 3: Energy barriers when isolated $\mathrm{Y}_{\mathrm{Zr}}^{\prime}$ at the $i$ th layer migrates to an isolated $\mathrm{V}_{\mathrm{Zr}}^{4 \prime}$ site at the $j$ th layer $[\mathrm{eV}]$.

\begin{tabular}{cccccccc}
\hline & \multicolumn{7}{c}{$j$ th layer } \\
\cline { 2 - 7 }$i$ th layer & 1 & 2 & 3 & 4 & 5 & 6 & $E_{i \text {,ave }}$ \\
\hline 1 & 2.12 & 3.03 & - & - & - & - & 2.58 \\
2 & 2.93 & 3.01 & 3.84 & - & - & - & 3.26 \\
3 & - & 4.05 & 3.91 & 4.48 & - & - & 4.15 \\
4 & - & - & 4.16 & 4.42 & 4.49 & - & 4.36 \\
5 & - & - & - & 4.08 & 4.46 & 4.46 & 4.33 \\
6 & - & - & - & - & 4.15 & 4.31 & 4.23 \\
\hline
\end{tabular}

Table 4: Energy barriers when isolated $\mathrm{Ca}_{\mathrm{Zr}}^{\prime \prime}$ at the $i$ th layer migrates to an isolated $\mathrm{V}_{\mathrm{Zr}}^{4 \prime}$ site at the $j$ th layer $[\mathrm{eV}]$.

\begin{tabular}{cccccccc}
\hline & \multicolumn{7}{c}{$j$ th layer } \\
\cline { 2 - 7 }$i$ th layer & 1 & 2 & 3 & 4 & 5 & 6 & $E_{i \text {,ave }}$ \\
\hline 1 & 0.72 & 2.03 & - & - & - & - & 1.38 \\
2 & 1.72 & 2.16 & 2.33 & - & - & - & 2.07 \\
3 & - & 2.37 & 2.42 & 2.68 & - & - & 2.49 \\
4 & - & - & 2.49 & 2.50 & 2.62 & - & 2.54 \\
5 & - & - & - & 2.47 & 2.45 & 2.53 & 2.48 \\
6 & - & - & - & - & 2.29 & 2.50 & 2.40 \\
\hline
\end{tabular}

Table 5: Energy barriers when $\mathrm{Zr}^{\times}$at the $i$ th layer migrates to an isolated $\mathrm{V}_{\mathrm{Zr}}^{4 \prime}$ site at the $j$ th layer $[\mathrm{eV}]$.

\begin{tabular}{cccccccc}
\hline & \multicolumn{7}{c}{$j$ th layer } \\
\cline { 2 - 7 }$i$ th layer & 1 & 2 & 3 & 4 & 5 & 6 & $E_{i \text {,ave }}$ \\
\hline 1 & 2.70 & 2.50 & - & - & - & - & 2.60 \\
2 & 2.71 & 4.30 & 4.28 & - & - & - & 3.76 \\
3 & - & 4.26 & 4.27 & 5.10 & - & - & 4.54 \\
4 & - & - & 4.77 & 4.97 & 5.02 & - & 4.92 \\
5 & - & - & - & 4.49 & 5.05 & 5.00 & 4.85 \\
6 & - & - & - & - & 4.71 & 4.70 & 4.71 \\
\hline
\end{tabular}


Table 6: Energy barriers when $\mathrm{Y}_{\mathrm{Zr}}^{\prime}$ at the $i$ th layer migrates to a $\mathrm{V}_{\mathrm{Zr}}^{4 \prime}$ site at the $j$ th layer $[\mathrm{eV}]$. Energy barriers are measured for a defect-complexes system consisting of $\left(2 \mathrm{Y}_{\mathrm{Zr}}^{\prime}, \mathrm{V}_{\mathrm{O}}^{\bullet \bullet}\right)^{\times}$and $\left(\mathrm{V}_{\mathrm{Zr}}^{4 \prime}, 2 \mathrm{~V}_{\mathrm{O}}^{\bullet \bullet}\right)^{\times}$. The average value and standard deviation (parentheses) for five samples are shown.

\begin{tabular}{|c|c|c|c|c|c|c|c|}
\hline \multirow[b]{2}{*}{$i$ th layer } & \multicolumn{6}{|c|}{$j$ th layer } & \multirow[b]{2}{*}{$E_{i \text { ave }}$} \\
\hline & 1 & 2 & 3 & 4 & 5 & 6 & \\
\hline 1 & $2.58(0.51)$ & $2.69(0.57)$ & - & - & - & - & 2.64 \\
\hline 2 & $3.25(0.47)$ & $3.52(0.43)$ & $3.46(0.49)$ & - & - & - & 3.41 \\
\hline 3 & - & $4.06(0.26)$ & $3.74(0.63)$ & $3.89(0.36)$ & - & - & 3.90 \\
\hline 4 & - & - & $3.80(0.35)$ & $3.82(0.55)$ & $3.99(0.41)$ & - & 3.87 \\
\hline 5 & - & - & - & $3.94(0.59)$ & $3.67(0.29)$ & $3.94(0.33)$ & 3.85 \\
\hline 6 & - & - & - & - & $3.85(0.40)$ & $3.77(0.54)$ & 3.81 \\
\hline
\end{tabular}

Table 7: Energy barriers when $\mathrm{Ca}_{\mathrm{Zr}}^{\prime \prime}$ at the $i$ th layer migrates to a $\mathrm{V}_{\mathrm{Zr}}^{4 \prime}$ site at the $j$ th layer $[\mathrm{eV}]$. Energy barriers are measured for a defect-complexes system consisting of $\left(\mathrm{Ca}_{\mathrm{Zr}}^{\prime \prime}, \mathrm{V}_{\mathrm{O}}^{\bullet \bullet}\right)^{\times}$and $\left(\mathrm{V}_{\mathrm{Zr}}^{4 \prime}, 2 \mathrm{~V}_{\mathrm{O}}^{\bullet \bullet}\right)^{\times}$. The average value and standard deviation (parentheses) for five samples are shown.

\begin{tabular}{cccccccc}
\hline & \multicolumn{7}{c}{$j$ th layer } \\
\cline { 2 - 8 } th layer & 1 & 2 & 3 & 4 & 5 & 6 & $E_{i \text {,ave }}$ \\
\hline 1 & $1.53(0.53)$ & $1.80(0.52)$ & - & - & - & - & 1.67 \\
2 & $1.83(0.36)$ & $1.99(0.26)$ & $1.88(0.24)$ & - & - & - & 1.90 \\
3 & - & $2.20(0.33)$ & $2.27(0.25)$ & $2.31(0.28)$ & - & - & 2.26 \\
4 & - & - & $2.28(0.21)$ & $2.56(0.28)$ & $2.22(0.29)$ & - & 2.35 \\
5 & - & - & - & $2.30(0.10)$ & $2.46(0.08)$ & $2.27(0.10)$ & 2.34 \\
6 & - & - & - & - & $2.33(0.27)$ & $2.32(0.11)$ & 2.33 \\
\hline
\end{tabular}

Table 8: Energy barriers when $\mathrm{Zr}^{\times}$at the $i$ th layer migrates to a $\mathrm{V}_{\mathrm{Zr}}^{4 \prime}$ site at the $j$ th layer $[\mathrm{eV}]$. Energy barriers are measured for a defect-complexes system consisting of $\left(\mathrm{V}_{\mathrm{Zr}}^{4 \prime}, 2 \mathrm{~V}_{\mathrm{O}}^{\bullet \bullet}\right)^{\times}$. The average value and standard deviation (parentheses) for five samples are shown.

\begin{tabular}{cccccccc}
\hline & \multicolumn{7}{c}{$j$ th layer } \\
\cline { 2 - 8 }$i$ th layer & 1 & 2 & 3 & 4 & 5 & 6 & $E_{i \text {,ave }}$ \\
\hline 1 & $2.45(0.39)$ & $3.14(0.54)$ & - & - & - & - & 2.80 \\
2 & $3.24(0.43)$ & $3.48(0.34)$ & $3.77(0.37)$ & - & - & - & 3.50 \\
3 & - & $5.04(0.42)$ & $4.15(0.33)$ & $4.42(0.42)$ & - & - & 4.54 \\
4 & - & - & $4.19(0.23)$ & $4.61(0.57)$ & $4.99(0.30)$ & - & 4.60 \\
5 & - & - & - & $4.44(0.40)$ & $4.57(0.44)$ & $4.75(0.57)$ & 4.59 \\
6 & - & - & - & - & $4.88(0.35)$ & $4.59(0.36)$ & 4.74 \\
\hline
\end{tabular}



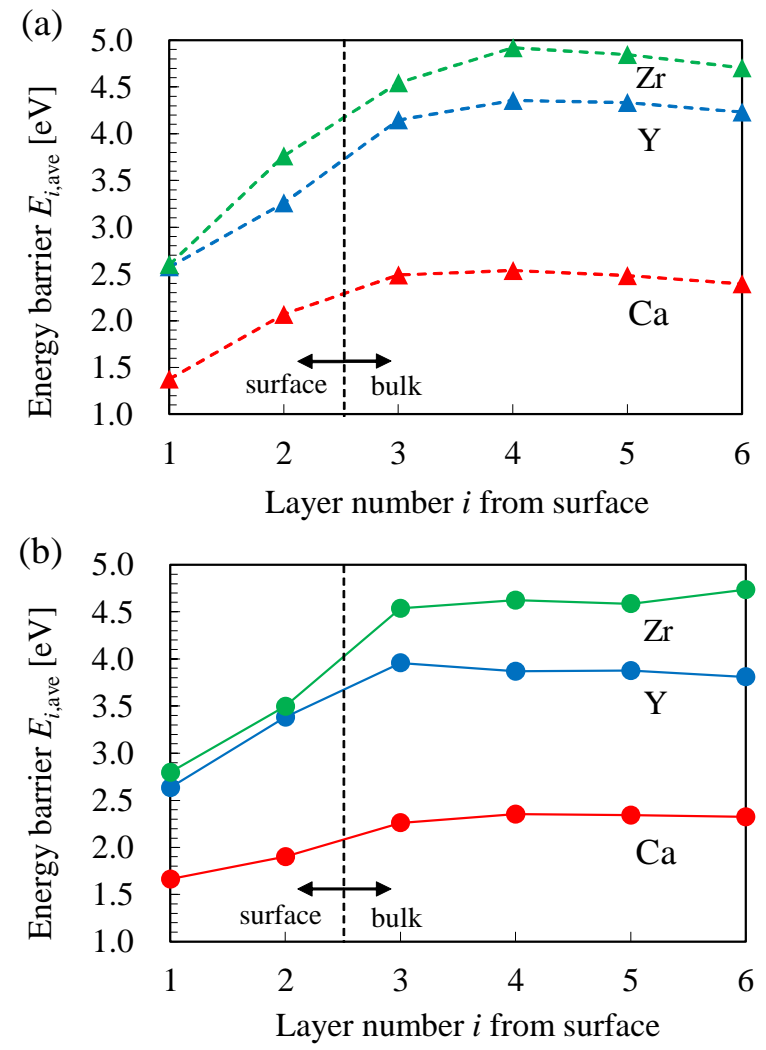

Figure 4: Averaged migration barrier $E_{i \text {,ave }}$ for each cations $\left(\mathrm{Y}_{\mathrm{Zr}}^{\prime}, \mathrm{Ca}_{\mathrm{Zr}}^{\prime \prime}\right.$, and $\left.\mathrm{Zr}^{\times}\right)$as a function of the layer number from the top surface estimated for (a) defect-isolated and (b) defect-complexes systems.

$\left.\mathrm{eV})>\mathrm{Ca}_{\mathrm{Zr}}^{\prime \prime}(\sim 2.5 \mathrm{eV})\right)$. The obtained activation energy for bulk is sufficiently comparable to the experimental value for $\mathrm{Zr}$ diffusion in $10 \mathrm{~mol} \% \mathrm{YSZ}$ ( $4.6 \mathrm{eV}$ [49]) estimated using secondary ion mass spectroscopy. Clearly, the barriers involving the first and second layers are much lower than those of the bulk. The values at the first layer are found to be approximately $60 \%$ that of 315 bulk for the three spices. Similar values are found for $\mathrm{Zr}^{\times}$and $\mathrm{Y}_{\mathrm{Zr}}^{\prime}(2.6$ 
$\mathrm{eV}$ ) and an even lower values is found for $\mathrm{Ca}_{\mathrm{Zr}}^{\prime \prime}(1.4 \mathrm{eV})$. The results for the defect-complexes case (Fig凹(b)) display a coincident tendency with the defect-isolated case. The barriers below the third layer for $\mathrm{Zr}^{\times}, \mathrm{Y}_{\mathrm{Zr}}^{\prime}$, and $\mathrm{Ca}_{\mathrm{Zr}}^{\prime \prime}$ are approximately $4.6,3.9$, and $2.3 \mathrm{eV}$, which are slightly lower than the defect-isolated case. Slightly higher barriers for the first layer are obtained, i.e., $2.8,2.6$, and $1.7 \mathrm{eV}$, respectively. Thus, for both the surface and bulk, independent of the defect type, the migration barrier of $\mathrm{Ca}$ is significantly lower (approximately 50\%) than that of Zr.

To further consider the effects of oxygen vacancy on migration kinetics, 325 we evaluate the energy barrier difference, $E_{\text {diff }}$, as a function of layer position (denoted by the midpoint), where a defect jumps between the $i$ th and $(i+1)$ th layer.

$$
E_{\text {diff }}\left(\frac{2 i+1}{2}\right)=E_{i \rightarrow i+1}-E_{i+1 \rightarrow i}
$$

Barrier difference $E_{\text {diff }}$ corresponds to the total energy difference associated with the configuration before and after cation hopping, shown schemat330 ically in Fig. 5. Thus, the positive value of $E_{\text {diff }}$ (Fig. 5(a)) indicates that the probability of a cation jump from bulk to surface $P_{i+1 \rightarrow i}$ is higher than that for the opposite direction $\left(P_{i \rightarrow i+1}\right)$.

In Fig. 6, we show the results of $E_{\text {diff }}$ with respect to the layer number from the surface for both $\mathrm{Y}_{\mathrm{Zr}}^{\prime}$ and $\mathrm{Ca}_{\mathrm{Zr}}^{\prime \prime}$ movements, focusing on the comparison between the defect-isolated and defect-complexes systems. It is found that $E_{\text {diff }}$ of $\mathrm{Y}_{\mathrm{Zr}}^{\prime}$ for both systems are nearly constant and positive at the bulk region (below the third layer), displaying higher values for the defectisolated system than for the defect-complexes system. However, the obvious 
(a)

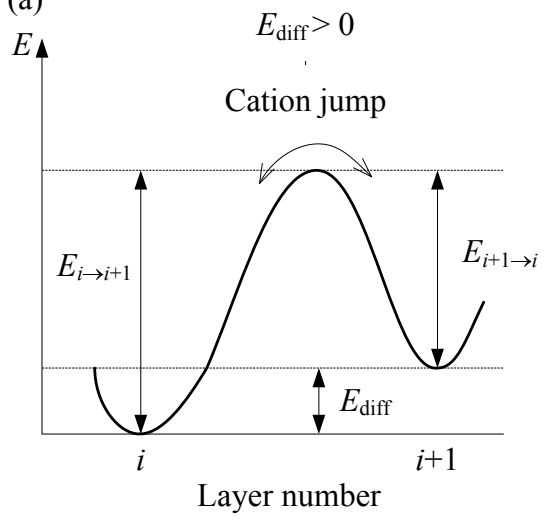

(b)

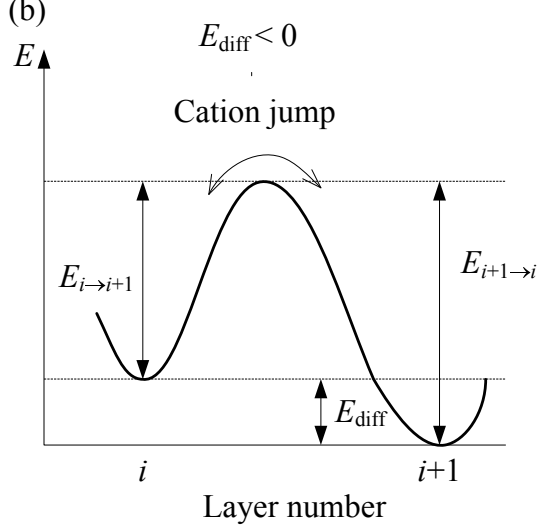

Figure 5: Schematic illustrations of the energy profile associated with the cation jump between the $i$ th and the $(i+1)$ th layer, where $E_{i \rightarrow i+1}$ is the energy hopping barrier from the $i$ th layer to the $(i+1)$ th layer, $E_{i+1 \rightarrow i}$ is the energy hopping barrier for the opposite direction, and $E_{\text {diff }}$ corresponds to the energy difference between two metastable states; (a) $E_{\text {diff }}>0$, (b) $E_{\text {diff }}<0$.

drop of $E_{\text {diff }}$ values can be detected between the second and third layers where the averaged migration energy $E_{i \text {,ave }}$ exhibits transition (Fig. 4). In particular, the $E_{\text {diff }}$ for $\mathrm{Y}_{\mathrm{Zr}}^{\prime}$ in the defect-complexes system decreases to a larger negative value $(-0.6 \mathrm{eV})$ between the second and third layers than in the defect-isolated system and maintains similar at the surface layer. For instance, at a typical firing temperature for the fabrication of dense YSZ ${ }_{345}\left(\sim 1400{ }^{\circ} \mathrm{C}\right)$, a $E_{\text {diff }}$ of $-0.6 \mathrm{eV}$ can yield a forward transition rate ratio of approximately 0.015 , i.e., $P_{i+1 \rightarrow i} / P_{i \rightarrow i+1} \sim 0.015$. Thus, forward jumping is unlikely when the jump species is subjected to a local environment with a high density of $\mathrm{V}_{\mathrm{O}}^{\bullet \bullet}$. Compared to other defect complexes, this energy difference would be caused by the stronger energy gain when the defect complexes 
350 temperatures, which could lead to the complexes depth profile of the chemical composition near YSZ surfaces, as shown in the previous experiments. 


\subsection{Surface Diffusion Analysis}

375 This section describes how the enrichment of a dopant or impurity at the surface affects the in-plane surface diffusivity for both cation and oxygen. Since cation self-diffusion, which involves a relatively high energy barrier, is uncommon in an MD framework with a limited time scale, we employed
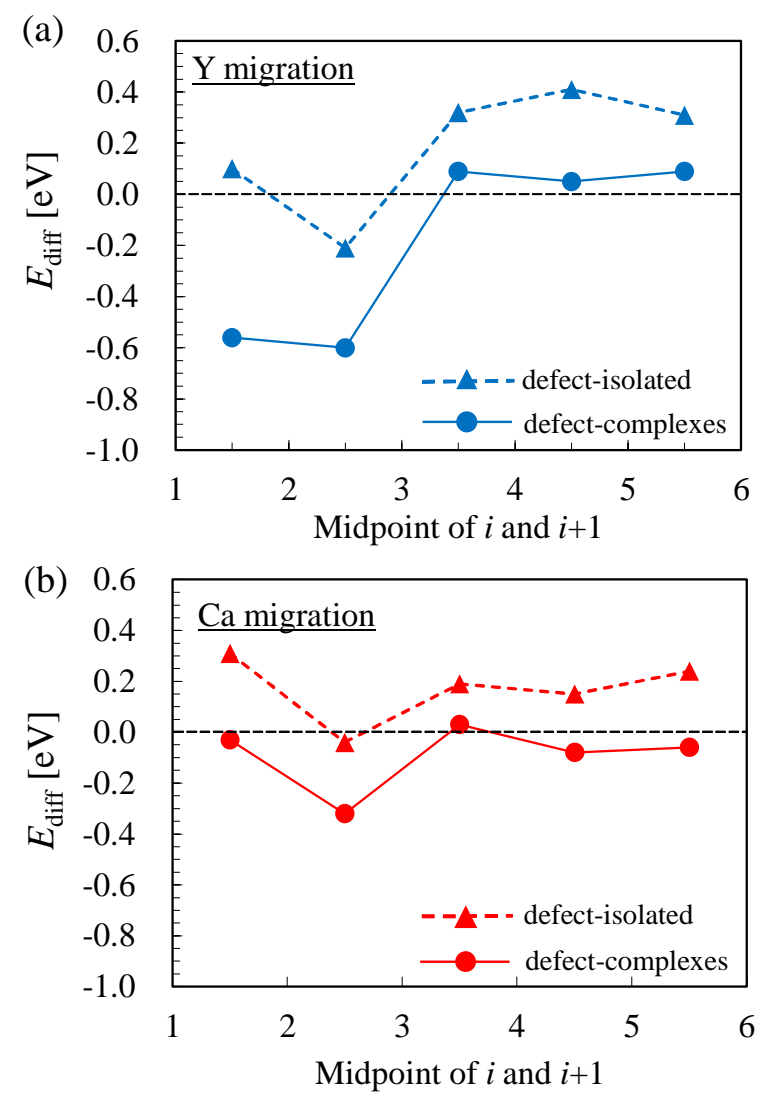

Figure 6: Energy barrier difference $E_{\text {diff }}$ between $E_{i \rightarrow i+1}$ and $E_{i+1 \rightarrow i}$ with respect to the layer number from top surface for (a) $\mathrm{Y}_{\mathrm{Zr}}^{\prime}$ and (b) $\mathrm{Ca}_{\mathrm{Zr}}^{\prime \prime}$ cations, where $E_{i \rightarrow i+1}$ corresponds to the activation hopping barrier from the $i$ th layer to the $j$ th layer. Results for defectisolated and defect-complexes systems for both cations are shown. 
a standard KMC technique, which is a useful tool for exploring long-time ble cation movements between layers $i$ and $j$ via cation vacancies. Within approximations from harmonic transition theory, each hopping rate can be simply described as $P_{i \rightarrow j}=P_{0} \exp \left(-E_{i \rightarrow j} / k_{\mathrm{B}} T\right)$, where $P_{0}$ is a typical attempt 
frequency of $10^{13}(1 / \mathrm{s})$ and $k_{\mathrm{B}}$ is Boltzmann constant. Here, the NEB results deduce from the defect-complexes systems (listed in Tables 6-8 for Y, $\mathrm{Ca}$, and $\mathrm{Zr}$ cations, respectively) are used as $E_{i \rightarrow j}$ input, as long as the $E_{i \rightarrow j}$ values are independent of the local concentration of dopant. The system configurations are evolved using a basic KMC algorithm [51] during $10^{7}$ steps under the given $C_{\mathrm{s}}\left(10 \sim 90\right.$ atom\%) and $T\left(600 \sim 1000{ }^{\circ} \mathrm{C}\right)$ conditions. For each run, the self-diffusion coefficients of cations at surface $D_{\mathrm{s}}^{\text {cat }}$ are extracted from the relationship between the mean square displacement (MSD) and the time $t\left(\mathrm{MSD}=4 D_{\mathrm{s}}^{\mathrm{cat}} t\right)$. Then, the Arrhenius slope is plotted to estimate the apparent activation energy of in-plane cation diffusion at surface $E_{\text {act }}^{\text {cat }}$.

The obtained $E_{\text {act }}^{\text {cat }}$ are shown in Fig. 7(a) as a function of $C_{\mathrm{s}}$. In addi415 tion, the self-diffusion coefficients of $\mathrm{Y}$ and $\mathrm{Ca}$ at $T=1000{ }^{\circ} \mathrm{C}$, normalized by the coefficients of $\operatorname{Zr}\left(D_{\mathrm{s}}^{\mathrm{Y}} / D_{\mathrm{s}}^{\mathrm{Zr}}\right.$ and $\left.D_{\mathrm{s}}^{\mathrm{Ca}} / D_{\mathrm{s}}^{\mathrm{Zr}}\right)$ are shown in Fig. Z(b) for the same segregation level range. It is found that the activation energy of cations at the Y-segregated surface do not exhibit clear dependence on chemical composition of $\mathrm{Y}$ at the surface because the migration barriers $\left(E_{1 \rightarrow 1}\right)$ for $\mathrm{Y}$ and $\mathrm{Zr}$ are similar values, i.e., 2.58 and $2.45 \mathrm{eV}$, respectively. Moreover, these values are well matched with the estimated activation energy $E_{\text {act }}^{\text {cat }}$ (approximately $2.5 \mathrm{eV}$ ), which indicates that the in-plane surface diffusion is primarily governed at the outermost layer. Similarly, $D_{\mathrm{s}}^{\mathrm{Y}} / D_{\mathrm{s}}^{\mathrm{Zr}}$ is nearly constant ( 0.3), independent of the dopant segregation level. Conversely, the strong dependence of the activation energy of cation $E_{\text {act }}^{\text {cat }}$ on the segregation level appears in the case of the Ca-segregated surface. The activation energy $E_{\text {act }}^{\text {cat }}$ decreases nonlinearly with increasing $C_{\mathrm{s}} ; E_{\text {act }}^{\text {cat }}$ shows the maximum drop at approximately $C_{\mathrm{s}}=30 \%$, hereafter followed by a slow decrease. At high 
$C_{\mathrm{s}}$ near full coverage, the $E_{\text {act }}^{\text {cat }}$ approaches $1.5 \mathrm{eV}$, which is identical to the migration energy of $E_{1 \rightarrow 1}$ for $\mathrm{Ca}(1.53 \mathrm{eV})$. Fig. [7(b) clearly shows that the Ca diffusivity can be significantly enhanced as the impurity level increases. Assuming the case of an extremely enriched Ca surface $\left(C_{\mathrm{s}} \sim 90 \%\right)$, it is possible to attain $D_{\mathrm{s}}^{\mathrm{Ca}} / D_{\mathrm{s}}^{\mathrm{Zr}}$ of approximately $10^{3}$. Thereby, the in-plane mass transport ability of a Ca-segregated surface, showing strong dependence on the chemical composition, is significantly higher than that of a Y-segregated surface.

Several experimental studies have revealed that the activation energy associated with the creep deformation of YSZ or Ni-YSZ at a temperature approximating that of SOFC operation $\left(<1100{ }^{\circ} \mathrm{C}\right)$ was found to be in the range of 1.0 to $2.0 \mathrm{eV}$ [5, 54, 55]. Laurencin et al. suggested that these barriers characterized the surface diffusion of a cation, which was also consistent with our KMC simulations. Furthermore, our results suggest that wide range of experimentally measured values may arise from the surface segregation level of impurities. In other words, controlling and reducing the amount of surface segregation will make it possible to improve the durability of YSZ electrolytes.

\subsubsection{Oxygen diffusion at surface}

Here, the MD models are the same as the model shown in Fig. 1. The first and second layers are enriched by $\mathrm{Y}$ or $\mathrm{Ca}$ for given concentrations of $C_{\mathrm{s}}$ and the layers below third layer are assumed to be a $10 \mathrm{~mol} \% \mathrm{YSZ}$ system. The corresponding number of oxygen vacancies was introduced into the systems, followed by initial equilibration at $1000{ }^{\circ} \mathrm{C}$ for $10 \mathrm{ps}$. Then, the MSD of the surface layers is calculated during a 500 ps run under the given $C_{\mathrm{s}}$ 

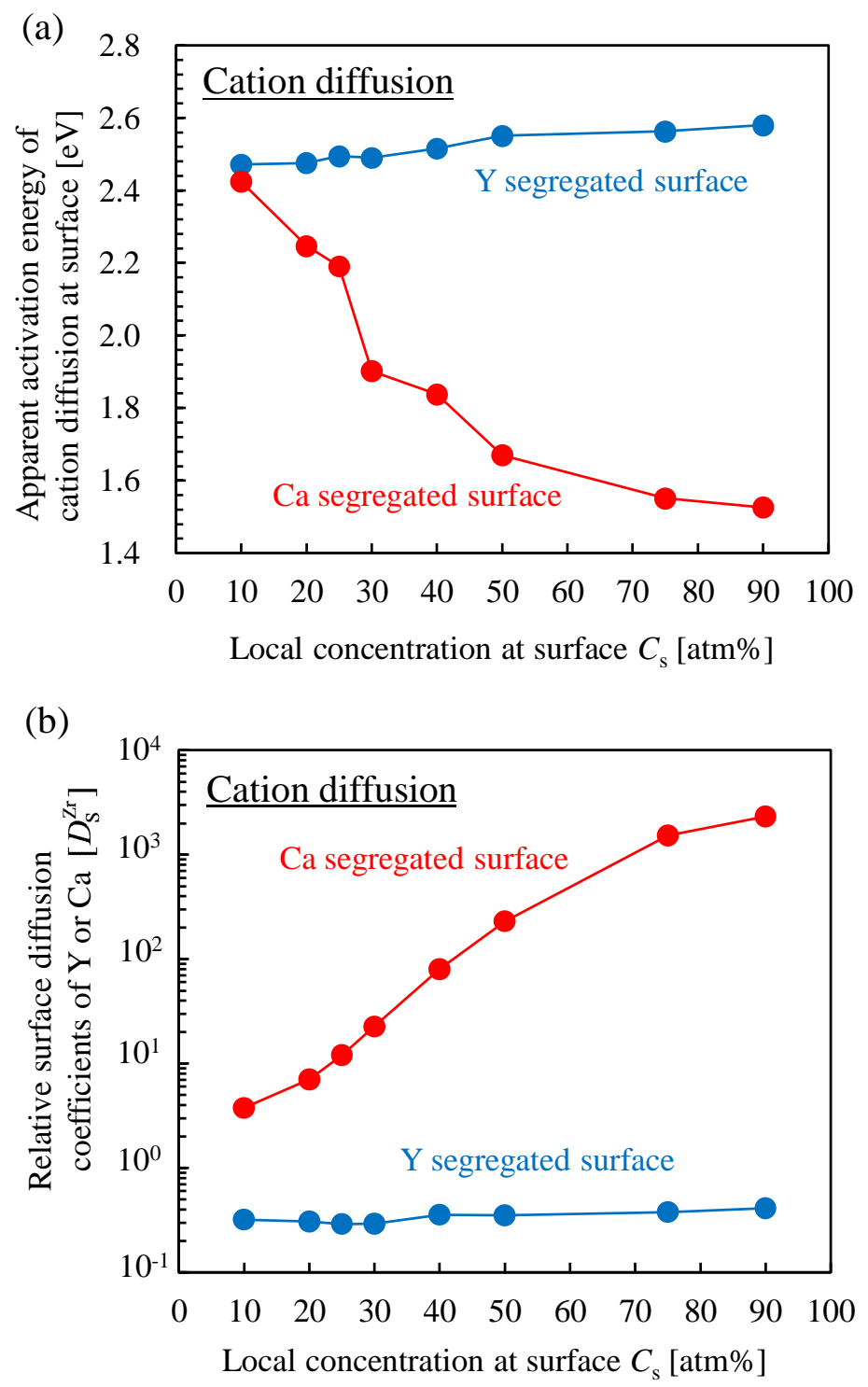

Figure 7: KMC simulation results for in-plane surface diffusion of cations; (a) apparent activation energy for cation diffusion as a function of $\mathrm{Y}$ or Ca concentrations at surface (b) surface diffusion coefficients for $\mathrm{Y}$ or Ca measured at $1000{ }^{\circ} \mathrm{C}$ as a function of $\mathrm{Y}$ or $\mathrm{Ca}$ concentration at the surface. The values are normalized by $\mathrm{Zr}$ value. 
(18.2 75.0 atom\%) and $T\left(1000 \sim 2227{ }^{\circ} \mathrm{C}\right)$ conditions. For each condition,

three samples starting from different initial velocities are examined to reduce the statistical error. Finally, the self-diffusion coefficients of oxygen $D_{\mathrm{s}}^{\text {oxy }}$ (averaged over three samples) and the related activation energy $E_{\text {act }}^{\text {oxy }}$ are obtained in a manner similar to that of the KMC simulations.

The results for activation energy $E_{\mathrm{act}}^{\mathrm{oxy}}$ as a function of the concentration $C_{\mathrm{s}}$ are shown in Fig. 8(a). The relationship between the self-diffusion coefficients $D_{\mathrm{s}}^{\text {oxy }}$ at $T=1000{ }^{\circ} \mathrm{C}$ (normalized by that for $10 \mathrm{~mol} \% \mathrm{YSZ}$, i.e., $D_{\mathrm{s}, 18.2}^{\mathrm{oxy}}: 18.2$ atom $\% \mathrm{Y}$ at the surface) and the concentration $C_{\mathrm{s}}$ are shown in Fig. 8(b). Our simulations indicate that the activation energy $E_{\text {act }}^{\text {oxy }}$ increases linearly from 0.57 to $1.01 \mathrm{eV}$ as the concentration of $\mathrm{Y}$ increases from 20 to 75 atom\%. As shown in Fig. 8(a), this linear dependence is consistent with the MD simulation results for oxygen diffusion in bulk YSZ (10 25YSZ) reported by Devanathan et al. [53. However, the main difference between the surface and bulk is that the activation barrier at the surface is lower than that of bulk for equal concentration. In addition, sensitivity to concentration is reduced. Oxygen diffusion coefficients at the Y-segregated surface decreases monotonically as the concentration increases, as shown in Fig. 8(b). It is also found that the dependence of diffusion coefficients at the surface on the concentration is less sensitive than that of bulk $D_{\mathrm{b}}^{\text {oxy }}$. As estimated in this study, the local equilibrium concentration of $\mathrm{Y}$ at the surface is approximately $C_{\mathrm{s}}^{\mathrm{eq}}=46 \%$ when the concentration of bulk is assumed to be $C_{\mathrm{b}}=18.2 \%$ (10YSZ). Under this equilibrium condition, our MD results predict that the oxygen diffusion coefficients at 46 atom\% Y-segregated surface $\left(D_{\mathrm{s}, 46}^{\text {oxy }}\right)$ is approximately equal to that at 18.2 atom\% YSZ bulk $\left(D_{\mathrm{b}, 18.2}^{\text {oxy }}\right)$. 
In addition, as shown in Fig. 8, the trend of oxygen diffusion properties for

indicate that both $\mathrm{Y}$ and $\mathrm{Ca}$ as well as cation vacancies become more stable near the surface, especially when co-segregated with oxygen vacancies. At a 

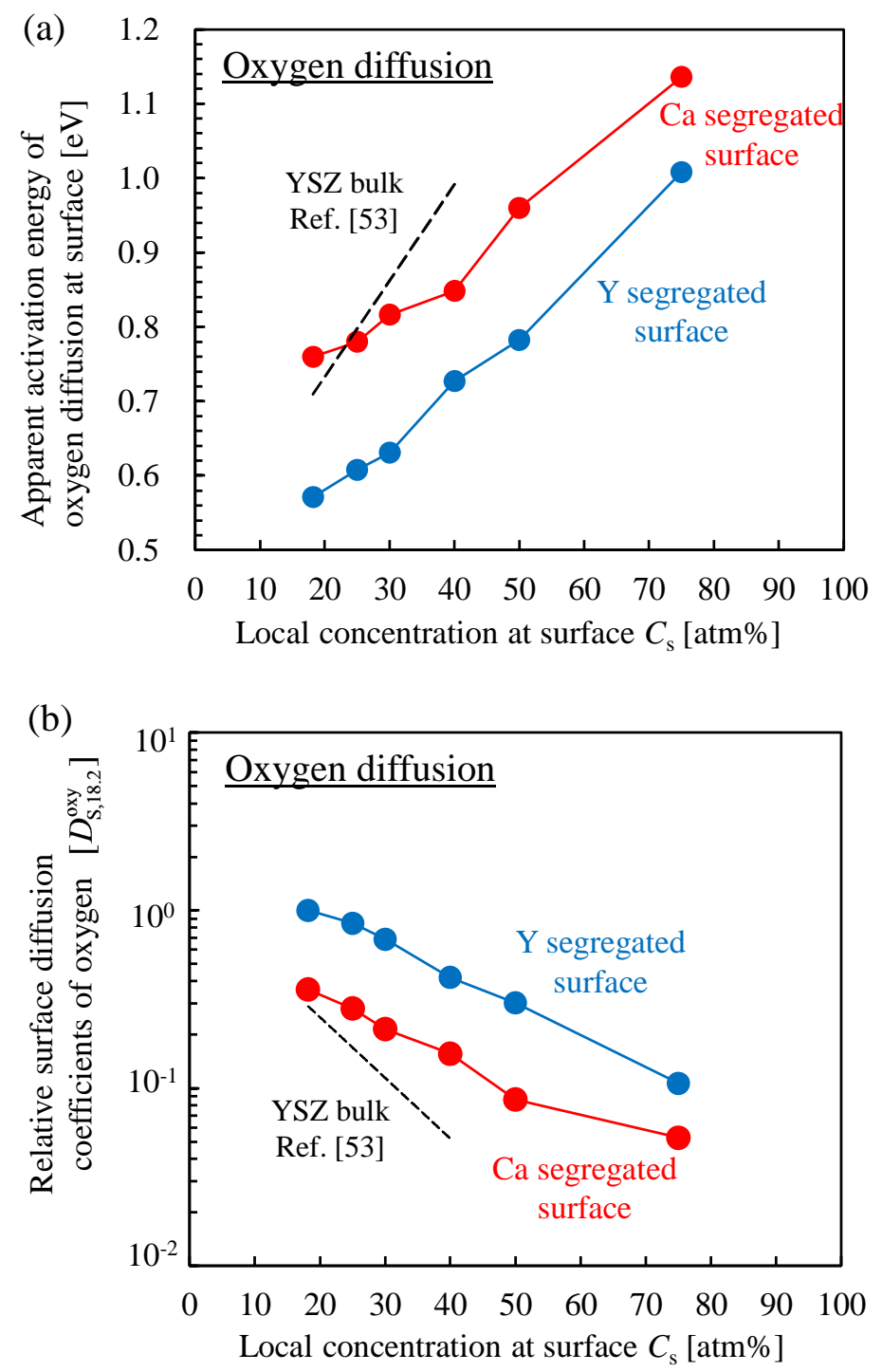

Figure 8: MD simulations results for in-plane surface diffusion of oxygen. (a) Apparent activation energy for oxygen diffusion as a function of $\mathrm{Y}$ or $\mathrm{Ca}$ concentrations at the surface. Dotted line indicates barrier data for YSZ bulk obtained using the MD reported in Ref. [53]. (b) Surface diffusion coefficients for oxygen measured at $1000{ }^{\circ} \mathrm{C}$ as a function of Y or Ca. Values are normalized by that estimated for $10 \mathrm{~mol} \%$ YSZ (18.2 Y atom\%). 
dilute limit condition, $\mathrm{Ca}$ is more energetically stable than $\mathrm{Y}$ at the surface; however, increased Ca concentrations at the surface is accompanied by a more

505 electrolyte in SOFC systems.

\section{Acknowledgments}

The authors acknowledge financial support from the Japan Science and Technology Agency CREST program. Yu Sun acknowledges support from 525 the 111 project (B07050) and the Institute for Computational Mechanics and Its Applications as well as Project 11402206 supported by the National 
Natural Science Foundation of China.

\section{References}

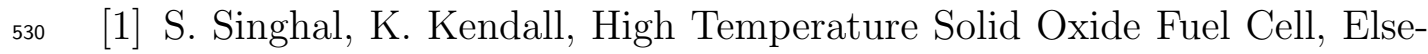
vier, 2002.

[2] B. C. Steele, A. Heinzel, Materials for fuel-cell technologies, Nature 414 (6861) (2001) 345-352.

[3] A. Atkinson, S. Barnett, R. Gorte, J. Irvine, A. Mcevoy, M. Mogensen, S. Singhal, J. Vohs, Advanced anodes for high-temperature fuel cells, Nature Materials 3 (2004) 17-27.

[4] E. Ivers-Tiffëe, A. Dirk Herbstritt, Materials and technologies for sofccomponents, Journal of the European Ceramic Society 21 (2001) 18051811.

${ }_{540}^{5}$ [5] J. Laurencin, G. Delette, F. Usseglio-Viretta, S. Di Iorio, Creep behaviour of porous SOFC electrodes: Measurement and application to Ni-8YSZ cermets, Journal of the European Ceramic Society 31 (2011) 1741-1752.

[6] I. Chen, S. Kim, J. Li, S. L. Kang, F. Huang, Ionomigration of neutral $545 \quad$ phases in ionic conductors, Advanced Energy Materials 2 (2012) 13831389. 
[7] M. De Ridder, R. Van Welzenis, H. Brongersma, U. Kreissig, Oxygen exchange and diffusion in the near surface of pure and modified yttriastabilised zirconia, Solid State Ionics 158 (1) (2003) 67-77.

550

[14] S. Alder, Factors governing oxygen reduction in solid oxide fuel cell cathodes, Chemical Reviews 104 (2004) 4791-4843. 
570

[15] A. Kumar, F. Ciucci, A. N. Morozovska, S. V. Kalinin, S. Jesse, Measuring oxygen reduction/evolution reactions on the nanoscale, Nature Chemistry 3 (2011) 707-713.

[16] H. Brongersma, M. de Ridder, A. Gildenpfennig, M. Viitanen, Insight in the outside: materials science at the atomic level using LEIS, Journal

[17] K. Norrman, K. Hansen, M. Mogensen, Time-of-flight secondary ion mass spectrometry as a tool for studying segregation phenomena at nickel-YSZ interfaces, Journal of the European Ceramic Society 26 (2006) 967-980.

[18] A. Hughes, S. Badwal, Impurity segregation study at the surface of yttria-zirconia electrolytes by XPS, Solid State Ionics 40 (1990) 312315.

[19] A. Hughes, S. Badwal, Impurity and yttrium segregation in yttriatetragonal zirconia, Solid State Ionics 46 (3) (1991) 265-274.

[20] M. De Ridder, R. Van Welzenis, A. D. van der Gon, H. Brongersma, S. Wulff, W. F. Chu, W. Weppner, Subsurface segregation of yttria in yttria stabilized zirconia, Journal of applied physics 92 (6) (2002) 30563064 .

[21] J. Nowotny, C. Sorrell, T. Bak, Segregation in zirconia: Equilibrium 590 versus non-equilibrium segregation, Surface and interface analysis 37 (3) (2005) 316-324. 
[22] V. Vonk, N. Khorshidi, A. Stierle, H. Dosch, Atomic structure and composition of the yttria-stabilized zirconia (111) surface, Surface science 612 (2013) 69-76.

595

600

[28] X. Xia, R. Oldman, R. Catlow, Computational modeling study of bulk and surface of yttria-stabilized cubic zirconia, Chemistry of Materials 21 (15) (2009) 3576-3585. 
[29] A. Chroneos, B. Yildiz, A. Tarancon, D. Parfitt, J. Kilner, Oxygen diffusion in solid oxide fuel cell cathode and electrolyte materials: Mechanistic insights from atomistic simulations, Energy \& Environmental Science 4 (2011) 2774-2789.

[30] X. G. Wang, Yttrium segregation and surface phases of yttria-stabilized zirconia (111) surface, Surface Science 602 (1) (2008) L5-L9.

[31] A. Marinopoulos, First principles study of segregation to the $\sigma 5(310)$ grain boundary of cubic zirconia, Journal of Physics: Condensed Matter 23 (8) (2011) 085005.

[32] H. B. Lee, F. B. Prinz, W. Cai, Atomistic simulations of surface segregation of defects in solid oxide electrolytes, Acta Materialia 58 (6) (2010) $2197-2206$.

[33] J. Lahiri, A. Mayernick, S. L. Morrow, B. E. Koel, A. C. T. van Duin, M. J. Janik, M. Batzill, Modification of active sites on YSZ(111) by yttria segregation, The Journal of Physical Chemistry C 114 (2010) 5990-5996.

[34] A. D. Mayernick, M. Batzill, A. C. Van Duin, M. J. Janik, A reactive force-field (ReaxFF) monte carlo study of surface enrichment and step structure on yttria-stabilized zirconia, Surface Science 604 (17) (2010) 1438-1444.

[35] M. Yoshiya, T. Oyama, Impurity and vacancy segregation at symmetric 635 tilt grain boundaries in $\mathrm{Y}_{2} \mathrm{O}_{3}$-doped $\mathrm{ZrO}_{2}$, Journal of materials science 46 (12) (2011) 4176-4190. 
[36] S. Swaroop, M. Kilo, C. Argirusis, G. Borchardt, A. H. Chokshi, Lattice and grain boundary diffusion of cations in 3YTZ analyzed using SIMS, Acta materialia 53 (19) (2005) 4975-4985.

[37] M. Kilo, M. Taylor, C. Argirusis, G. Borchardt, R. Jackson, O. Schulz, M. Martin, M. Weller, Modeling of cation diffusion in oxygen ion conductors using molecular dynamics, Solid State Ionics 175 (1) (2004) $823-827$.

[38] R. González-Romero, J. Meléndez, D. Gómez-García, F. Cumbrera, A. Domínguez-Rodríguez, F. Wakai, Cation diffusion in yttria-zirconia by molecular dynamics, Solid State Ionics 204 (2011) 1-6.

[39] G. Ballabio, M. Bernasconi, F. Pietrucci, S. Serra, Ab initio study of yttria-stabilized cubic zirconia surfaces, Physical Review B 70 (2004) 075417.

[40] C. A, G. Buskerb, Solution mechanisms for $\mathrm{Li}_{2} \mathrm{O}$ in $\mathrm{Sc}_{2} \mathrm{O}_{3}, \mathrm{Y}_{2} \mathrm{O}_{3}$ and $\mathrm{La}_{2} \mathrm{O}_{3}$, Acta Chimica Slovenica 52 (2005) 417-421.

[41] M. Kilo, C. Argirusis, G. Borchardt, A. Jackson, Oxygen diffusion in yttria stabilised zirconia-experimental results and molecular dynamics calculations, Physical Chemistry Chemical Physics 5 (2003) 2219-2224.

[42] R. Pornprasertsuk, P. Ramanarayanan, C. Musgrave, F. Prinz, Predicting ionic conductivity of solid oxide fuel cell electrolyte from first principles, Journal of Applied Physics 98 (10) (2005) 103513.

[43] A. Dwivedi, A. Cormack, A computer simulation study of the defect structure of calcia-stabilized zirconia, Philosophical Magazine A-Physics 

(1990) 1-22.

[44] G. Henkelman, H. Jónsson, Improved tangent estimate in the nudged elastic band method for finding minimum energy paths and saddle points, The Journal of Chemical Physics 113 (2000) 9978.

[45] S. Hara, S. Izumi, S. Sakai, Reaction pathway analysis for dislocation nucleation from a Ni surface step, Journal of applied physics 106 (2009) 093507.

[46] Y. Sun, S. Izumi, S. Sakai, K. Yagi, H. Nagasawa, Core element effects on dislocation nucleation in 3C-SiC: Reaction pathway analysis, Computational materials science 79 (2013) 216-222.

[47] D. Wolf, Reconstruction of $\mathrm{NaCl}$ surfaces from a dipolar solution to the Madelung problem, Physical Review Letters 68 (1992) 3315-3318.

[48] T. Oyama, M. Yoshiya, H. Matsubara, K. Matsunaga, Numerical analysis of solute segregation at $\sigma 5(310) /[001]$ symmetric tilt grain boundaries in $\mathrm{Y}_{2} \mathrm{O}_{3}$-doped $\mathrm{ZrO}_{2}$, Physical Review B 71 (2005) 224105.

[49] M. Kilo, G. Borchardt, B. Lesage, O. Kaitasov, S. Weber, S. Scherrer, Cation transport in yttria stabilized cubic zirconia: ${ }^{96} \mathrm{Zr}$ tracer diffusion in $\left(\mathrm{Zr}_{x} \mathrm{Y}_{1-x}\right) \mathrm{O}_{2-x / 2}$ single crystals with $0.15 \leqslant \mathrm{x} \leqslant 0.48$, Journal of the European Ceramic Society 20 (12) (2000) 2069-2077.

${ }_{680}$ [50] Y. Toyofuku, T. Hosoi, T. Kawabata, Y. Shiratori, S. Taniguchi, K. Sasaki, Durability of SOFCs using inexpensive Ca-doped $\mathrm{ZrO}_{2}$ electrolytes, ECS Transactions 57 (1) (2013) 807-813. 
[51] A. Voter, Introduction to the kinetic monte carlo method, Radiation effects in solids 235 (2007) 1-23.

[52] M. Khan, M. Islam, D. Bates, Cation doping and oxygen diffusion in zirconia: A combined atomistic simulation and molecular dynamics study, Journal of Mterials Chemistry 8 (1998) 2299-1307.

[53] R. Devanathan, W. Weber, S. Singhal, J. Gale, Computer simulation of defects and oxygen transport in yttria-stabilized zirconia, Solid State Ionics 177 (2006) 1251-1258.

[54] R. Soltani, T. Coyle, J. Mostaghimi, Creep behavior of plasma sprayed zirconia thermal barrier coatings, Journal of the American Ceramic Society 90 (2007) 2873-2878.

[55] G. Thurn, G. Schneider, F. Aldinger, High-temperature deformation of 695 plasma-sprayed $\mathrm{ZrO}_{2}$ thermal barriers coatings, Materials Science and Engineering A233 (1997) 176-182. 